\title{
Assessment of pulmonary vascular volume and lung perfusion in patients with hypoplastic left heart syndrome (HLHS) in Fontan-circulation
}

\author{
Carsten Rickers ${ }^{1 *}$, Eileen Pardun ${ }^{1}$, Michael Jerosch-Herold², Dominik Gabbert ${ }^{1}$, Chris Hart ${ }^{1}$, Inga Voges ${ }^{1}$, \\ Andreas Entenmann ${ }^{1}$, Hans Heiner Kramer ${ }^{1}$
}

From 2011 SCMR/Euro CMR Joint Scientific Sessions

Nice, France. 3-6 February 2011

\section{Introduction}

Data from catheter angiography indicate that children with Hypoplastic Left Heart Syndrome (HLHS) in Fontan circulation have hypoplastic central pulmonary arteries. We used novel MRI techniques to quantify pulmonary vascular volume and lung perfusion in a cohort of HLHS patients and a group of healthy control subjects.

\section{Methods}

We investigated 31 children $(4,9 \pm 2,3$ yrs $)$ with HLHS, and 6 lung healthy children $(9,8 \pm 6,4 \mathrm{yrs})$. A modified contrast-enhanced dynamic MR-angiography sequence was used to assess pulmonary vascular volume and total lef and right lung volumes. CMR software was used to measure, total lung volume, and the up-slope of the signal intensity curves, as well as the mean transit time (MTT), in order to assess pulmonary perfusion.

\section{Results}

The indexed pulmonary total lung volume and the relative vascular volume in HLHS was significantly reduced compared to the control group $(650 \pm 102$ vs. $945 \pm 274$ $\mathrm{ml} / \mathrm{m}^{2}, \mathrm{p}=0.049 ; 6.5 \pm 3.7$ vs. $\left.9 ., 5 \pm 2.4 \% / \mathrm{m}^{2}, \mathrm{p}=0.03\right)$. There were no differences of the right and the left side of the lungs within the two groups. Lung perfusion in children with HLHS was also impaired (MTT: $10.8 \pm 2$ vs. $6.7 \pm 3 \mathrm{~s}, \mathrm{p}=0.004$; Up-slope: $4.8 \pm 2,6$ vs. $10.1 \pm 5.8 \mathrm{~s}$ $\left.1 \mathrm{~m}^{2} ; \mathrm{p}=0,075\right)$. There were no differences of the right and the left side of the lungs within the two groups. Additionally, we found a weak correlation between cardiac index $(2.78 \pm 0,82 \mathrm{ml} / \mathrm{m} 2 / \mathrm{min})$ and lung perfusion $(\mathrm{r}=0.34, \mathrm{p}=0 ., 062)$. Additionally, we found a correlation between cardiac index $\left(2,78 \pm 0,82 \mathrm{ml} / \mathrm{m}^{2} / \mathrm{min}\right)$ and lung perfusion $(r=0,54, p<0,05)$ in those HLHS pts with the fenestration closed.

\section{Conclusions}

Advanced MRI methods enable the assessment of pulmonary perfusion in HLHS patients in Fontan circulation. HLHS patients have a reduced total lung volume, pulmonary vascular volume, and an impaired lung perfusion, compared to controls. The clinical significance of these findings for the Fontan circulation needs to be evaluated by long-term follow-ups.

\section{Author details}

'University Hospital Schleswig-Holstein, Kiel, Germany. ${ }^{2}$ Brigham and Womens Hospital, Harvard Medical School, Boston, MA, USA.

Published: 2 February 2011

doi:10.1186/1532-429X-13-S1-P198

Cite this article as: Rickers et al: Assessment of pulmonary vascular volume and lung perfusion in patients with hypoplastic left heart syndrome (HLHS) in Fontan-circulation. Journal of Cardiovascular Magnetic Resonance 2011 13(Suppl 1):P198.

${ }^{1}$ University Hospital Schleswig-Holstein, Kiel, Germany

Full list of author information is available at the end of the article

(c) 2011 Rickers et al; licensee BioMed Central Ltd. This is an open access article distributed under the terms of the Creative Commons 